\title{
Solution Structure of the Cytoplasmic Domain of Syndecan-3 by Two-dimensional NMR Spectroscopy
}

\author{
In Young Yeo, Bonkyung Koo, Eok-soo Oh, ${ }^{\dagger}$ Inn-Oc Han, ${ }^{\ddagger}$ and Weontae Lee \\ Department of Biochemistry and Protein Network Research Center, Ionsei Liniversity, Seoul 120-749, Korea \\ ${ }^{\star}$ E-mail: wlee aspin vonsei.ackr \\ ${ }^{\dagger}$ Department of Life Sciences, Division of Life and Pharmaceutical Sciences and the Center for Cell Signaling \& \\ Drug Discovery Research, Enha Homans Lniversitw, Seoul 120-750, Korea \\ ${ }^{\ddagger}$ Department of Phwsiologv and Biophwsics, Ihha Lniversity, Incheon 402-751, Korea \\ Received December 17, 2007
}

\begin{abstract}
Syndecan-3 is a cell-surface heparan sulfate proteoglycan which performs a variety of functions during cell adhension process. It is also a coreceptor for growth factor. mediating cell-cell and cell-matrix interaction. Syndecan-3 contains a cytoplasmic domain potentially associated with the cytoskeleton. Syndecan- 3 is specifically expressed in neuron cell and has related to neuron cell differentiation and development of actin filament in cell migration. Syndecans each have a unique. central. and variable (V) region in their cytoplasmic domains. And that region of syndecan-3 may modulate the interactions of the conserved $\mathrm{Cl}$ regions of the cytoplasmic domains by tỵ rosine phosphorylation. Cytoplasmic domain of syndecan-3 has been stythesized for NMR structural studies. The solution stnicture of syndecan-3 cytoplasmic domain has been determined by two-dimensional NMR spectroscopy and simulated-annealing calculation. The cytoplasmic domain of the syndecan proteins has a tendency to form a dimmer conformation with a central cavity. however. that of syndecan-3 demonstrated a monomer conformation with a flexible region near C-terminus. The structural information might add knowledge about the structure-function relationships among șindecan proteins.
\end{abstract}

Key Words : Syndecan-3. Proteoglycan, NMR

\section{Introduction}

The sy'ndecans are transmembrane heparan sulfate proteoglycans (HSPGs) that are present on most cell types. HSPGs have been known for some time to regulate a variety of biological processes. ranging from coagulation cascades. growth factor signaling. lipase binding and activity. cell adhesion to ECM and subsequent cytoskeletal organization. to infection of cells with microorganisms.

The syndecan family in vertebrates comprises four members. sy'ndecan-1. syndecan-2 (fibroglycan). syndecan3 (N-syndecan). and syndecan-4 (amphiglycan. ryudocan) ${ }^{1}$ and they have been identified by molecular colning from mammalian cells. In addition. syndecan proteoglycan has homolog identified in Drosophila and C. elegens." All syndecans have a common structure that possess a large extracellular domain with a signal peptide and varying amounts of glycosaminoglycan (GAG) attachment sites. a one transmembrane domain and a very short cytoplasmic domain. They have high sequence homology in the transmembrane and C-terminal domains. Syndecans play an important role in tissue morphogenesis and differentiation by virtue of their ability to bind a number of extracellular adhesive proteins and growth factors. Also. an essential feature of the functional activity of syndecans is their ability to associate with actin filaments.

The cytoplasmic domain of syndecans consists of constants regions $(\mathrm{Cl}$ and $\mathrm{C} 2)$. with an intervening unique region (termed the variable ( $\mathrm{V}$ ) region). The $\mathrm{V}$ regions are conserved between species but differ between individual syindecans (syndecans 1-4).

All syndecans oligomerize to form ligher-order complexes. and oligomerization may underlie their biological roles. The self-interaction of the cytoplasmic domains has only been investigated for sy'ndecan-4 so far. Short sy'nthetic peptides having the sequence of syndecan- $4 \mathrm{~V}$ region form dimers with a parallel twisted clamp structure. ${ }^{4.5}$ Chemical crosslinking of syndecan- 3 core proteins expressed on the surface of transfected cells reveals that most of the core proteins are present in oligomeric form. Self-association of $\mathrm{N}$-syndecan core protein to form stable. noncovalent multimeric complexes requires the presence of the trancmembrane domain as well as a short extracellular domain sequence that is conserved in syndecan core protein sequences. ${ }^{6}$

Syndecan 3 is found in neuronal tissues and developing musculoskeletal cells. It is also termed $\mathrm{N}$-syndecan due to its abundant in the nervous system was first cloned in rat from a schwann cell and a rat brain library. ${ }^{7.8}$ Its expression strongly correlates with the differentiation of oligodendrocytes and myelination in the central and peripheral nervous systems. ${ }^{9}$ This syindecan. unlike the others. appears to bind ECM components poorly. Indeed. it may function more in growth factor control of adhesion. Its heparan sulfate chains can bind HB-GAM. which results in axonal extension. ${ }^{2.5}$ Binding results in axonal extension. concomitant with an interaction of the $\mathrm{Cl}$ region of its cytoplasmic domain with a complex that includes c-src and the syndecan-3 substrate cortactin and tubulin. ${ }^{10}$ 
In the study of syndecan-3V structure. we provide the characteristic of syndecan-3V structure and indicate the position of specific binding of ligand for syndecans. This data might add infornation about the structure-function relationships and provide a structural background for further study. In this report, we present the solution structure of the syndecan-3V peptide to analyze its local conformation using two dimensional NMR spectroscopy and dynamical simullated-annealing calculations

\section{Materials and Methods}

Peptide synthesis. Syndecan-3V (Ac-Len-Glu-Glu-ProLys-Gln-Ala-Ser-Val-Thr-Tyr-Ghn-Lys-NH:) corresponding to residues Leul ${ }^{+21}$ to $L y s^{43 \hat{3}}$ of the syndecan-3 cytoplasmic domain was synthesized conmercially (Anygen Co., Kuvangu, Korea). The synthetic peptide was purified by reverse-phase liquid chromatography using a Shim-Pack C 18 column on a Water Delta Prep 4000 system. The peptide was purified using a reverse-phase $\mathrm{Cl} 18$ column with $0.1 \%$ trifluoroacetic acid (TFA) in water and developing with a linear gradient of acetonitrile. The purified peptides were funally characterized by combined use of high-performance liquid chromatography (HPLC) and mass spectrometry (MS). The theoretical mass expected for syndecan-3V was 1562.9. The peptide sample for NMR experinents was prepared by dissolving in $100 \% \mathrm{D}_{2} \mathrm{O}$ and $90 \% \mathrm{H}_{2} \mathrm{O} / 10 \% \mathrm{D}_{2} \mathrm{O}$. Solution is at $\mathrm{pH}$ value of 7.0 with $50 \mathrm{mM}$ potassium phosphate buffer. The final peptide concentration was $2.7 \mathrm{mM}$ in 0.5 $\mathrm{mL}$ of buffer solution

Circular dichroism spectroscopy. CD spectra of $50 \mu \mathrm{M}$ syndecan-3V were measured in $50 \mathrm{mM}$ potassium phosphate buffer for designed various $\mathrm{pH}$. temperatures and micelle conditions using a Jasco J-810 spectropolarimeter. CD spectra were recorded from 190 to $250 \mathrm{~nm}$ at a scanning rate $50 \mathrm{~nm} \cdot \mathrm{min}^{-1}$ with a time constant of $0.5 \mathrm{sec}$. Each CD spectrum was obtained from an average of 10 accuntulations with step resolution of $0.2 \mathrm{~nm}$ and bandwidth of $2.0 \mathrm{~nm}$ in cells with $0.1 \mathrm{~mm}$ path length

NMR spectroscopy. NMR spectra were acquired at 278 $\mathrm{K}$ on Bruker DRX-500 spectrometers equipped with a tripleresonance probe with $x, y, z$-shielded pulsed-field gradient coil. Two-dimensional (2D) NMR spectra were recorded in phase-sensitive mode using time-proportional phase incrementation (TPPI) ${ }^{11}$ for quadrature detection in the $t_{1}$ domain. The 2D experiments such as total correlation spectroscopy (TOCSY) ${ }^{12}$ using a MLEV-17 spin-lock pulse sequence with a mixing time of $69.8 \mathrm{~ms}$ and nuclear overhauser enhancement spectroscopy (NOESY) ${ }^{1 \hat{3}}$ with mixing times of 200 ms-600 ms were performed. Solvent suppression for TOCSY and NOESY experiments was achieved using a WATERGATE pulse sequence ${ }^{14}$ combined with pulsed-field gradient pulse. All NMR spectra were acquired with 2048 complex data points in $t_{2}$ and 256 increments in the $t_{1}$ dimension. with 64 scan per increment. All NMR data were processed on a Silicon Graphics Indigo II workstation using nunrPipe/ numrDraw or XWIN-NMR (Bruker Instruments. Karlsruhe.
Germany) software and analyzed using the Sparky 3.60 program. ${ }^{15}$ The proton chemical shifts were expressed relative to the methyl resonance of the internal sodium 2.2dimethyl-2-silapentane-5-sulfonic acid (DSS).

Structural restraints and structure calculations. Distance restraints were derived from the NOESY spectra in $90 \% \mathrm{H}_{2} \mathrm{O} / 10 \% \mathrm{D}_{2} \mathrm{O}$ solution. A total of $170 \mathrm{NOE}$ constraints were used for structure calculations. Cross-peak volumes were divided as strong. medium and weak. corresponding to upper bound interproton distance restraints of $2.7,3.3$ and $5.0 \AA$, respectively. The structures were calculated using the hybrid distance geometry and dynamical simulated annealing (SA) protocol, as previously described. ${ }^{16-19}$ using the CNS 1.1 program on a Linux workstation. Final structures were analyzed using PROCHECK ${ }^{2 i j}$ and displayed using Insight II (Biosym/Molecular Simulations, Inc.) and MOLMOL programs. ${ }^{. j}$

\section{Results and Discussion}

Circular dichroism spectroscopy. The CD spectrum of the syndecan-3V peptide (sequence LEEPKQASVTYQK) at $\mathrm{pH} 7.0$ and $25^{\circ} \mathrm{C}$ does not show any standard secondary structures (data not shown). ${ }^{.2}$ However, the structure of the syndecan $-3 \mathrm{~V}$ based on $\mathrm{CD}$ data demonstrated as a loop conformation with several tums as previously reported $4 \mathrm{~V}$ peptide.

NMR resonance assignments. There are one serine, tyrosine and alanine residues in the syndecan-3V peptide sequence. The one alanine residue was identified from comectivities in TOCSY spectra by its characteristic methyl resonance and the lone tyrosine residue was easily assigned by combined use of TOCSY and NOESY spectra. The single unique serine residue was also assigned from the TOCSY spectrum. These preliminary resonance assignments served as starting points for the sequence specific assignment procedure. ${ }^{23}$

Complete proton resonance assigument for syndecan-3V was achieved using the standard sequential resonance assignment procedure ${ }^{23}$ Once the individual spin systems had been classified. backbone sequential resonance assignment was easily completed by $d_{\alpha \AA}(i, i+\mathrm{l})$ NOE comnectivities in the 2D-NOESY spectra. The side chain assignment was performed with TOCSY connectivities (Fig. 2A). Figure 1 sunmmarizes the observed sequential and medium range $\mathrm{NOE}$ connectivities for the syndecan-3V. Figure 2B shows NH/NH region of NOESY spectrum to demonstrate $d_{\mathrm{N}}$ NOEs. In the NOESY spectra, a number of $d_{\mathrm{N} N}$ crosspeaks from the amide noe region were observed but it can not prove the presence of $\alpha$-helix. Other NOEs confirm that standard regular secondary structure does not exist. Sequencial NOE region was assigned in $\alpha \mathrm{N}$ region of NOESY spectra. It does not presented here for overlapping. The aliphatic proton resonance region of the two-dimensional NOESY spectrum of syndecan-3V display NOEs assigned with intramolecular NOEs as well as intermolecular NOEs (In this report. the data was not displayed). All NOEs were 


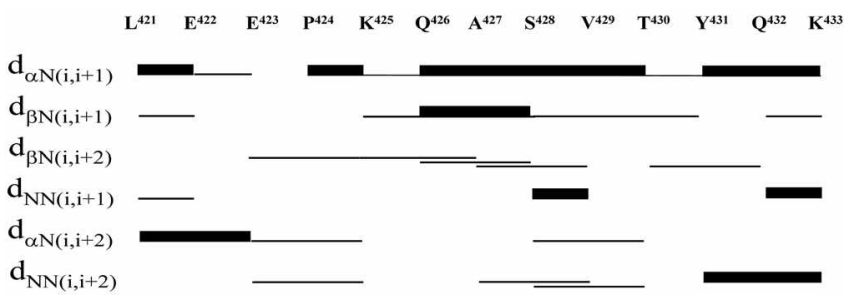

Figure 1. Summary of the NOE connectivities identified in syndecan-3V at $25^{\circ} \mathrm{C}, \mathrm{pH} 7.0$. The observed NOE intensities are classified by the thickness of the lines.

observed at mixing times of $600 \mathrm{~ms}$.

The proton chenical shifts for the individual residues in syndecan-3V peptide are in excellent agreement with the corresponding randon coil values. ${ }^{\hat{4}}$ As expected for a highly flexible peptide, $\mathrm{NH}-\mathrm{CaH}$ coupling constants for all the residues are of the order of $6.58 .0 \mathrm{~Hz}$, suggesting retention of significant conformational flexibility. In addition, the sequential NOE intensities displayed a form that has not a secondary structure.

Solution structure of the syndecan-3V. The NMR structures for syndecan-3V were calculated using the experjmental constraints derived from both 2D-TOCSY and 2DNOESY spectra. A total of 100 starting substructures were calculated in the initial sinulated annealing stage. After two cycles of the sinulated anneal protocol, 95 structures which showed no constraint violations greater than $0.5 \AA$ for distances and $5^{\circ}$ for torsion angles were identified. Among 95 structures. the 18 lowest-energy structures $(<\mathrm{SA}>\mathrm{k})$ were selected for structural analysis (Table 1). The structures are well defined with a root-mean-square-deviation between backbone atom coordinates of $0.29 \AA$ for residues Glu2-Val 9. The average structure was generated from the geometrical average 18 structure coordinates and was subjected to restrained energy minimization to correct bond length and angle distortions. This average structure exhibited $0.68-\AA$ root-mean-square deviation for backbone atoms with respect to $18(<\mathrm{SA}>\mathrm{k})$ structures. A best-fit superposition of all final structures and the backbone conformation for the average restrained energy minimized stnucture $\left(\langle\overline{\mathrm{SA}}\rangle_{\mathrm{k}}\right)$ are displayyed in Figure $3(\mathrm{~A})$. The atomic average root-meansquare deviations of the final structures with respect to the average energy-minimized (REM) structure are shown in Figure 3(B). The Ramachandran plot indicates that $\Phi . \Psi$ torsion values of all 18 final NMR structures are distributed properly in energetically acceptable regions. ${ }^{\text {ts }}$

It has been reported that the central sequence of syndecan family plays an inportant role in oligomerization process. The variable domain of syndecan-4 binds and activates $\mathrm{PKC}$ through dimerization of the syndecan-4 cytoplasmic domain ${ }^{26}$ Serine phosphory lation in the cytoplasnic dontain inhibits both dimerization and PKC activation. ${ }^{27.88}$ But preceding study we know that syndecan-3 has a dimericationin in core protein. This is proved by glutaraldehyde crosslinking experiment. For dimerization of syndecan 3, transmembrane region must combine with cytoplasmic domain. Also the four residues in the forward of ecto domain have an
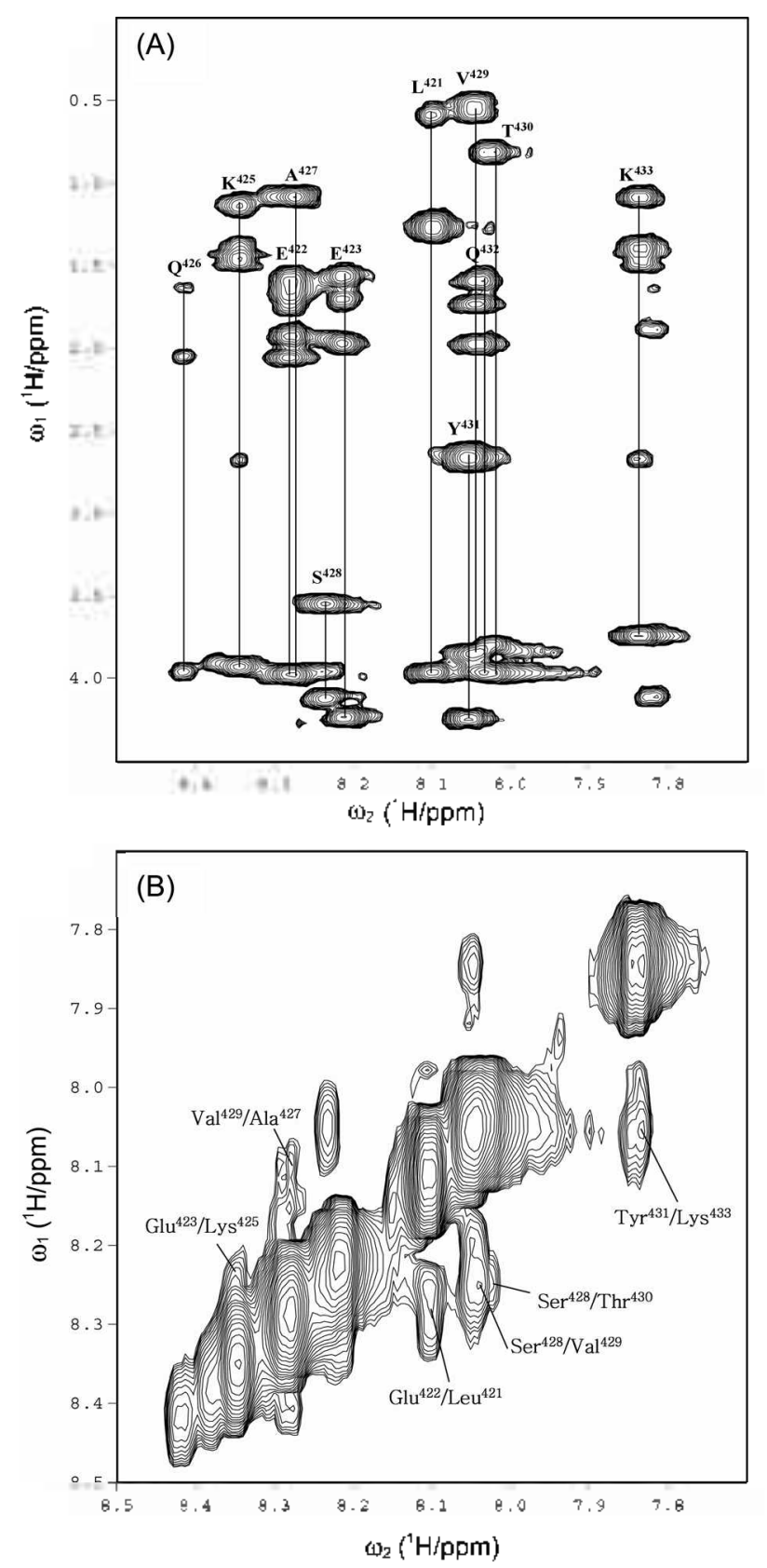

Figure 2. (A) Fingerprint region of 2D-TOCSY spectrum for syndecant-3V with mixing time of $69.8 \mathrm{~ms}$ at $25^{\circ} \mathrm{C}$. (B) Amide region of $2 \mathrm{D}$-NOESY spectrum for syndecan-3V with at mixing time of $600 \mathrm{~ms}$ in $90 \% \mathrm{H}_{2} \mathrm{O} / 10 \% \mathrm{D}_{2} \mathrm{O}$ solution at $25^{\circ} \mathrm{C}$ and $\mathrm{pH}$ value of 7.0 .

important role in dimerization. For the reasons. we thought that syndecan-3V was monomer condition and calculated structure of the only $\vee$ region in cytoplasmic domain that makes use to synthesized șyndecan-3V in solution.

Structure of the syndecan-3V has a high sequence homology with syndecan-1 V. It was only different to serine. threonine. and valine residues in central position of $v$ region. Then, we suggest that the residues play an important role in binding of the signaling molecules. Methyl group of one valine and alanine residue propose to hydrophobic interaction. The serine, tyrosine and threonine residues were 
Table 1. Structural statistics for the 18 final sinulated-annealing structures (SA) structures of syndecan-3V

\begin{tabular}{|c|c|c|}
\hline & $\langle\mathrm{SA}\rangle_{k}$ & $\langle\overline{\mathrm{SA}}\rangle_{\mathrm{kr}}$ \\
\hline \multicolumn{3}{|c|}{$\begin{array}{l}\text { (A) minsd from experimental distance } \\
\text { restraints }(\AA)\end{array}$} \\
\hline all $(170)$ & 0.0430 & 0.0418 \\
\hline sequential $(|i-j|=1)(59)$ & 0.0059 & 0.0061 \\
\hline inter residue $(8 \overline{5})$ & 0.0595 & 0.0579 \\
\hline intrat residue (85) & 0.0033 & 0.0034 \\
\hline \multicolumn{3}{|c|}{$\begin{array}{l}\text { (B) nns deviation of structural segment } \\
\left.\text { for }<\mathrm{SA}>\left(G \ln ^{2}-V_{a}\right]^{\circ}\right)(\AA)\end{array}$} \\
\hline backbone & $0.29 \pm 0.15$ & \\
\hline heavy atoms & $0.96 \pm 0.28$ & \\
\hline \multicolumn{3}{|l|}{ (C) Energies } \\
\hline $\mathrm{E}_{\text {total }}\left(\mathrm{kcal}_{\text {.mol }} \mathrm{l}^{-1}\right)$ & 39.65 & 38.13 \\
\hline ExoE (all) $\left(\mathrm{kcal}^{\mathrm{mol}} \mathrm{l}^{-1}\right)$ & 15.781 & 14.862 \\
\hline $\mathrm{E}_{\mathrm{tu}}\left(\mathrm{kcal}_{\mathrm{l}} \mathrm{mnol} \mathrm{l}^{-1}\right)$ & 18.873 & 18.576 \\
\hline $\mathrm{E}_{\mathrm{l} \cdot \mathrm{s}}\left(\mathrm{kcal} . \mathrm{mol}^{-1}\right)^{a}$ & -6.578 & -4.961 \\
\hline \multicolumn{3}{|c|}{$\begin{array}{l}\text { (D) Deviations from idealized covalent } \\
\text { geometry }\end{array}$} \\
\hline bonds $(\AA)$ & 0.0029 & 0.0028 \\
\hline angles (deg) & 0.5592 & 0.5349 \\
\hline impropers (deg) & 0.2808 & 0.2651 \\
\hline
\end{tabular}

" $E_{L, .1}$ is the Lennard-Tones Van der Waals potential calculated using CHARMm empirical energy function.

located to one surface to optimize molecular interaction. We suppose that their hydrosyl groups might mediate hydrogen bond interactions for protein-protein interaction (Fig. 4). Although syndecans do not themselves posses any cytoplasnic enzymatic activity, they are known to bind potential cytoplasmic signaling molecules. Syndecans have four conserved cytoplasmic tyrosine residues. which can be phosphorylated ${ }^{p i s .31}$

Tyrosine phosphorylation can be blocked by inhibitor of

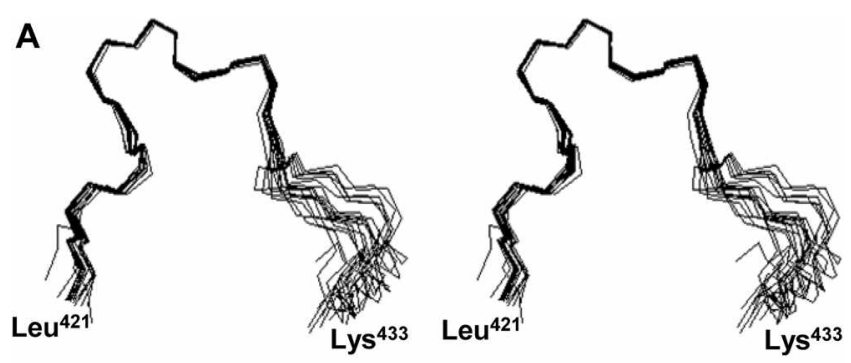

B

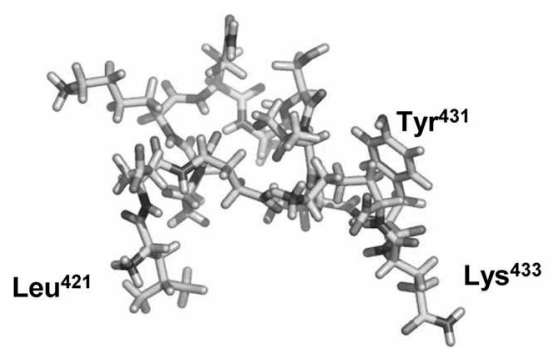

Figure 3. (A) A stereo view of the backbone superposition of the energy-minimized average structure $\left(\langle\mathrm{SA}\rangle_{\mathrm{W}}\right)$ over the tamily of 18 final simulated annealing structures $\left(\langle\mathrm{SA}\rangle_{\mathrm{ks}}\right)$. (B) REM structure of the syndecan-3V. The figure was generated using the pyMOL

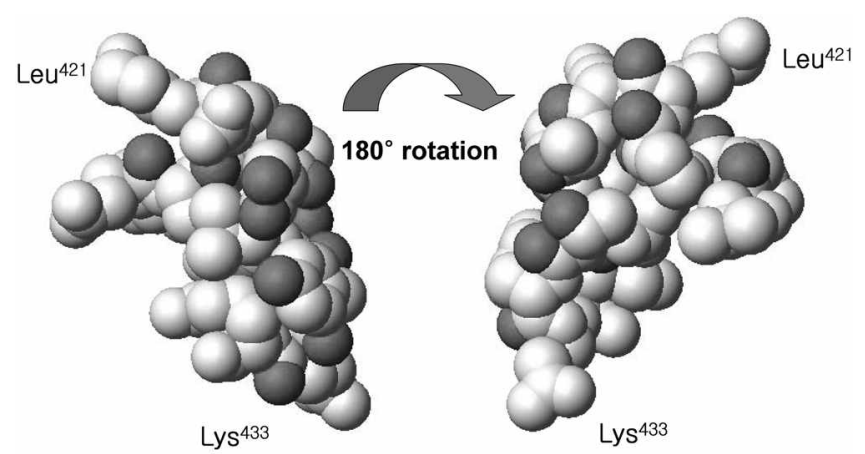

Figure 4. CPK model of syndecan-3V. The hydrosyl group of serine, threonine and tyrosine and oxygen atoms are presented in grey color.

src family kinase ${ }^{31}$ Syndecan could thus regulate cytoplasmic kinase activities and the activation may depend on ligand induced oligomerization of syndecan core proteins. As the structure calculation. syndecacn- $3 \mathrm{~V}$ has the clamp shape that was similar to structure of syndecan-IV. 4 V. On the structure. it was fitting well from residue $\mathrm{Glu}^{+23}$ to $\mathrm{Val}^{4+99}$. However. it was not fitting and has flexible form in the cterminal region. We are proposed that the flexible site helps the signaling molecules to binding at the syndecan. In this report. we provided the characteristic of its structure and indicate the position of specific binding of ligand for syndecans. This data could serve as an important information about the structure-function relationships. providing structural background for further biological functions of syndecan family proteins.

Acknowledgements. This work was supported by Korea Research Foundation Grant (KRF-2002-CP0327 to E.S.O. $\&$ W. Lee).

\section{References}

1. Carey. D. J. Biochem J. 1997.327. 1-16.

2. Tumova. S.: Woods. A.: Couchmant. T. R. In J Biochem Cell Biol. 2000. 32(3). 269-288.

3. Spring, J.: Paine-Saunders, S.; Hynes, R: Bernfield, M. Proc. Katl Acad Sci. U.S.t. 1994, 91.3334-3338.

4. Couchman. J. R.: Chen, L.; Woods. A. Iht Rev Cytol 2001. 207. 113-150.

5. Woods. A.: Couchman. I. R. J. Biol. Chem. 2000. 275. 2423324236 .

6. Asundi. V. K.: Carev, D. J. d. Biol. Chem. 1995. 270, 2640426410.

7. Carey, D. J.; Evans, D. M.: Stahl. R. C. Asundi, V. K: Conner, K. J.: Garbes. P. Cizmeci-Smith. G. J. Cell Biol 1992. 117(1). 191201 .

8. Carey. D. J.: Conner. K.: Asundi. V. K.: O'Mahony. D. T.: Stahl. R. C.: Showalter. L.: Cizmeci-Smith, G.: Hartman. J.: Rothblum, L. I. J. Biol. Chem. 1997. 272(5), 2873-2879.

9. Carey, D. J. Perspect Dev Kemobiol 1996, 3. 331-346.

10. Kint1unen. T. et al, J. Biol. Chent 1998. 273. 10702-10708.

11. Marion1. D.: Wuthrich. K. Biochem. Biophws Res. Commm. 1983. IJ3. 967.

12. Davis, D. G. Bax, A. J. Am. Chem. Soc. 1985, 107. 2820

13. Jeener. J:- Meier, B. H.; Bachman, P.: Enst, R. R. J. Chem. Phys. 1979. 71,4546 
14. Piotto. M.: Saudek. V: Sklenar. V. J. Bionol. M MR 1992. 2. 661.

15. Delaglio. F.: Grzesiek. S.: Vuister. G. W.: Zhu. G.: Pfeifer. J.: Bax. A. J. Biomol MTR $1995.6,277$.

16. Driscoll. P. C: Gronenbon. A. M: Beress. L.: Clore G. M. Biochemistry 1989, 28. 2188.

17. Nilges. M.: Clore. G. M.: Gronenborn. A. M. FEBS Lett. 1988. 229.317

18. Nilges. M.: Clore. G. M.: Gronenborn. A. M. FEBS Lett. 1988. 239. 129

19. Nilges. M: Gronenborn. A. M: Brunger A. T.: Clore. G. M. Protem Eng. 1988,2,27

20. Lakovski. R. A.: MacArthur. M. W.: Moss. D. S.: Thornton. J. M. J. Appl Crnstallogr: 1993. 26.283.

21. Koradi. R.: Billeter. M.: Wüthrich. K. J. Mol. Graphics 1996. If. 51.

22. Yang J. T.: Wu. C.S. C.: Martinez, H. M. Wethods Enzzmol. 1996, 130,208-269.
23. Wüthrich. K. MRR of Proteins and Nucleic Acids: Wisley: New York. 1986

24. Wishart. D. S.: Sykes. B. D.: Richards. F. M. J. Hol Biol 1991. 222. $311-333$

25. Morris, A. L. MacArthur. M. W.: Hutchison, E. G: Thornton. J. M. Proteins 1992. 12. 345-364.

26. Oh. E. S.: Woods. A.: Couchmant. T. R J. Biol. Chem. 1997. 272(18). 11805-11811

27. Horowitz. A.: Simons. M. J. Biol Chen. 1998. 273(40). 2554825551 .

28. Horowitz, A.; Simons, M. J. Biol. Chem 1998. 273(18), 1091410918.

29. Reiland. J.: Ott. V. L.: Lebakken. C. S.: Yeaman. C.: McCarthy. J.: Rapraeger. A. C. Biochent J. 1996. 319(Pt I). 39-47.

30. Asundi. V. K.: Carey. D. I. Biochent. Biophns Res. Conmum. 1997. $240(2), 502-506$

31. Ott. V. L.: Rapraeger. A. C. J. Biol. Chem. 1998, 273(52), 3529135298 . 